Delito, ley, colonialismo, poscolonialismo, Sur de Asia

\title{
LEGALIDADES E ILEGALIDADES: EL DELITO EN LA INDIA COLONIAL Y POSCOLONIAL
}

\author{
SAURABH DUBE \\ El Colegio de México
}

\section{ANUPAMA RAO \\ Universidad de Columbia}

No hace mucho, mientras planeábamos este proyecto -que comprende el presente ensayo y su predecesor-, nuestra mente se trasladó no al pasado sino al presente, a la literatura más que a la historia. Nos impresionó cómo The White Tiger, la reciente y galardonada novela de Aravind Adiga, planteó preguntas provocativas sobre el delito como práctica de crítica social. ${ }^{1}$ Esto nos recordó nuestras propias conversaciones sobre la centralidad de la ley, la violencia y el Estado en proyectos de acción colectiva y autocreación. En pocas palabras, en la obra de Adiga encontramos una exploración de la violencia en el odio de castas y la hostilidad de clases en la India globalizadora, y en la reproducción del privilegio a través de los registros distintos, aunque relacionados, de los modos de poder "feudales" y los "modernos".

Huelga decir que tales preocupaciones resuenan poderosamente con nuestros propios intentos por comprender el delito y la criminalidad como construcciones históricas. Producidas dentro de los intersticios de las relaciones entre Estado y sociedad y gobernadas por ideas cambiantes sobre conducta normativa y castigo legítimo, estas construcciones involucran siempre pasados que continúan hacia el presente. Si tales temas

Este artículo fue recibido por la dirección de la revista el 11 de septiembre de 2012 y aceptado para su publicación el 18 de abril de 2013.

${ }^{1}$ Aravind Adiga, The White Tiger, Nueva York, Free Press, 2008. 
se abordaron en el ensayo anterior, deberán aclararse más en el presente ejercicio.

Ahora, la preocupación central de la mirada etnográfica literaria de Adiga es la violencia contemporánea de la vida diaria, junto con la amoralidad de las clases medias emergentes de India, más generalmente. Con su burda y evidente propensión al consumo, hay grupos sociales que siguen dependiendo del servicio de una gran clase conformada por trabajadores domésticos —choferes, ayas, chaukidars - cuyo trabajo los sostiene. Más que su posesión de las últimas lavavajillas y televisores de plasma, lo que distingue a esta élite globalizadora es su poder sobre la mano de obra viva, que vive relegada a las habitaciones de los sirvientes, forzada a registrarse con la policía, que recibe pases para entrar a comunidades cerradas, siempre mal pagada, $y$ que con frecuencia recibe castigos corporales.

Así, aun cuando las formas culturales de subordinación jerárquica se redefinen y se legitiman cada vez más como trabajo asalariado, lo que vale la pena destacar es el temor presente en las clases medias a la violencia entre subalternos provocada por la disparidad de la riqueza. Este miedo convive con las aspiraciones (necesariamente cumplidas, siempre diferidas) de las clases medias, seducidas por interminables bienes de consumo y por la buena vida. Al mismo tiempo, la hostilidad entre los trabajadores domésticos y sus patrones incita una variedad de comportamientos de los primeros, desde el robo hormiga hasta la violencia de clases.

En la novela, Balram Halwai, testigo de primera mano de la degeneración ética de su amo, realiza a su vez un acto de "violencia purificadora": asesinarlo. Esta batalla a muerte entre amo y sirviente también es una lucha por el reconocimiento social. Aquí, Adiga sugiere que la brutalidad del sirviente se genera a partir de la mayor brutalidad de la sociedad y la hace posible. Al mismo tiempo, en lugar de recrear el orden social a través de la violencia revolucionaria, aquel que se encarga de asuntos turbios, el engañador y el estafador en la India urbana ahora se encuentra en el lugar del Estado, que incluye especialmente el monopolio de la violencia legítima.

La visión distópica de Adiga replica tendencias más amplias de las culturas popular y política actuales de India, que activan 
el intercambio mimético entre la ley y la violencia. Por ejemplo, tal engendramiento mutuo de lo lícito y lo ilícito estructura de manera significativa filmes populares sobre el submundo de Bombay (el primero de los cuales fue Satya de Ram Gopal Verma) que ahora dan forma a variaciones submetropolitanas de los bajos mundos, como Omkara. ${ }^{2}$ Asimismo, las simetrías y las asimetrías del orden y el exceso producidas en la exitosa Rang de Basanti se incorporan en la más independiente Nobody Killed Jessica Lal [Nadie asesinó a Jessica Lal], cada una como cine y como realidad. ${ }^{3} \mathrm{El}$ punto es que al tiempo que el Estado indio se retira de sus anteriores compromisos con el bienestar social y el otorgamiento de derechos colectivos, la violencia, en lugar de transformación pedagógica, parece ser el modo de comunicación política entre las clases sociales, mientras que las clases medias se oponen al Estado a través de sus derechos innatos.

No sorprende que incluso la mundialmente famosa Slumdog Millionaire, una suerte de obra de moralidad donde el oprimido obtiene el dinero y a la chica, plantee insistentemente cuestiones de relaciones sociales entre la élite y los subalternos. ${ }^{4}$ Sin embargo, a diferencia de modelos anteriores de rebelión colectiva o de lucha de clases, ahora se considera que el problema de la intimidad social involucra una violencia diaria cada vez mayor en las zonas urbanas del sur de Asia, debido a la potente combinación de una creciente disparidad económica y la democratización del deseo del consumidor. Además, desde las discusiones cotidianas sobre las estafas interminables de hoy -que implican a políticos, burócratas, empresarios y poderes en la

${ }^{2}$ Arjun Appadurai, "Spectral Housing and Ethnic Cleansing: Notes on Millennial Mumbai”, Public Culture, vol. 12, núm. 3, 2000, pp. 627-651; Sudipta Kaviraj, "Reading a Song of the City: Images of the City in Literature and Films", en Preben Kaarsholm (ed.), City Flicks: Indian Cinema and the Urban Experience, Calcuta, Seagull Books, 2004, pp. 60-82; Ashish Nandy, "Indian Popular Cinema as a Slum's Eye View of Politics", en Ashish Nandy (ed.), The Secret Politics of Our Desires: Innocence, Culpability and Popular Indian Cinema, Londres-Nueva York, Zed Books, 1999, pp. 1-19; Sandeep Pendse, "Bombay's Satya and Satya's Bombay”, en Sujata Patel y Jim Masselos (eds.), Bombay and Mumbai: The City in Transition, Oxford, Oxford University Press, 2003. Satya (hindi; director: Ram Gopal Varma, 1998); Omkara (hindi; director: Vishal Bhardwaj, 2006).

${ }^{3}$ Rang de Basanti (hindi, inglés, punjabi; director: Rakeysh Omprakash Mehra, 2006); Nobody killed Jessica Lal (inglés; director: Rajkumar Gupta, 2008).

${ }^{4}$ Slum Dog Millionaire (inglés; director: Danny Boyle, 2008). 
sombra - hasta la política tanto de la India corporativa como del movimiento Team Anna (Hazare), las representaciones contemporáneas de la criminalidad apuntan a un orden social inestable basado en la permeabilidad de la ley (del Estado) y la violencia (popular). En una u otra forma, el delito se encuentra en la mente de todo indio hoy en día.

El presente ensayo, como su predecesor, proporciona una genealogía de tales preocupaciones. A tono con los requisitos de una genealogía vivaz, aprovechamos no sólo las continuidades sino también las rupturas de la historia y sus lógicas, no sólo las conexiones sino también las discontinuidades de la cultura y sus expresiones. Si abarcamos el pasado y el presente, la historia y la antropología, y los estudios culturales y las perspectivas legales es con el fin de expresar cómo estos ámbitos y entendimientos se unen pero se rompen en pedazos. Todo esto nos permite dar un giro crítico particular al delito y la cultura para plantear preguntas e iniciar debates en torno de estos conceptos y procesos.

\section{Vigilancia y subversión}

El suceso del delito ocurre en los intersticios de las fuerzas sociales en competencia y pone en juego matrices entrelazadas de parentesco, comunidad, Estado y sujeto; sin embargo, una vez que se le declara culpable, el delincuente aparece en una relación dual, e incluso contrapuesta, con el Estado, pues se considera que insinúa un peligro social y también se le ve como prueba de la eficiencia del Estado en el control del delito. Dos prácticas de disciplina colonial, la encarcelación y la deportación a colonias penales, manifiestan las contradicciones de la reforma penal en un contexto colonial. ${ }^{5}$ Cada una produjo sus

\footnotetext{
${ }^{5}$ Clare Anderson, Convicts in the Indian Ocean: Transportation from South Asia to Mauritius, 1815-53, Londres, Macmillan, 2000; Satadru Sen, Disciplining Punishment: Colonialism and Convict Society in the Andaman Islands, Nueva Delhi-Oxford-Nueva York, Oxford University Press, 2000. La experiencia social del reo deportado y, más adelante, del jornalero contratado a largo plazo, no es nuestro objeto de estudio. No obstante, cabe destacar cómo la violencia doméstica encajó en las violentas dislocaciones espaciales de dicha mano de obra. Prabhu Mohapatra, "Restoring the Family: Wife Murders and the Making of a Sexual Contract for Indian Indentured Labourers in
} 
propias formas de subversión, lo que también permitió nuevas prácticas de autocreación colectiva y personal. Como instancia tangible - a la vez material y simbólica- de la ley colonial, la prisión se volvió un sitio experimental de reforma y mejoramiento penal, así como un espacio para resistir y subvertir la disciplina colonial.

Los argumentos en favor de la encarcelación eran afirmaciones en contra del castigo corporal. La reclusión se justificaba a través de dos conjuntos de lógicas: la primera derivada de una creencia en la posibilidad de reforma y rehabilitación a través de la ingeniería social, mientras que la segunda implicaba consideraciones humanitarias sobre lo que Michael Ignatieff llama una "justa medida de dolor" o la idea de la proporcionalidad en la administración del castigo. ${ }^{6}$ La humanidad del delincuente se descubrió a costa del derecho del soberano a castigar al criminal mediante el espectáculo violento, como argumentara hace mucho tiempo Michel Foucault; ${ }^{7}$ en este sentido, el antropólogo y teórico social Talal Asad ha abundado sobre cómo los conceptos cambiantes de castigo se vieron afectados por transformaciones en la soberanía. El argumenta que contra el telón de fondo de diversas alteraciones en las ciencias médicas, especialmente el desarrollo de la medicina forense, la cuantificación del dolor, es decir, la idea de que uno puede medir el dolor (y por tanto el sufrimiento humano), produjo un cambio significativo en las prácticas punitivas. La idea de calibrar el castigo para que se ajuste al delito se derivó de la creencia creciente en la integridad corporal como una condición necesaria del ser humano. ${ }^{8}$

the British Caribbean Colonies”, Studies in History, vol. 10, núm. 2, 1995, pp. 225260. También es bien conocido el uso del trabajo de los reos para obras públicas y producción de bienes de consumo, incluida una discusión de Sanjay Nigam, que se consideró en cierta medida el predecesor del presente ensayo. Véase también Chitra Joshi, "Fettered Bodies: Labouring on Public Works in Nineteenth Century India", en Marcel van der Linden y Prabhu Mohapatra (eds.), Labour Matters: Towards Global Histories, Nueva Delhi, Tulika Books, 2009, pp. 3-21, y Padmini Swaminathan, "Prison as Factory: A Study of Jail Manufacture in the Madras Presidency", Studies in History, vol. 11, núm. 77, 1995, pp. 77-100.

${ }^{6}$ Michael Ignatieff, A Just Measure of Pain: The Penitentiary in the Industrial Revolution 1750-1850, Nueva York, Pantheon Books, 1978.

${ }^{7}$ Michel Foucault, Discipline and Punish, Nueva York, Vintage Books, 1995.

${ }^{8}$ Talal Asad, "On Torture, or Cruel, Inhuman, and Degrading Treatment", en Arthur Kleinman, Veena Das y Margaret Lock (eds.), Social Suffering, Delhi, Oxford University Press, 1998, pp. 285-308. 
Al mismo tiempo, en estos terrenos se discuten historias discontinuas y procesos fracturados, algunos de los cuales presentamos ahora en trazos más o menos amplios, a la vez que incluimos detalles necesarios. Para empezar, el contexto colonial de la reforma penitenciaria produjo sus propias contradicciones. Al tiempo que la Comisión Legislativa de 1835 abordó la codificación legal y la reforma penitenciaria como temas interconectados, el sistema de prisiones colonial operó bajo la creencia de que los indígenas respondían mejor a la violencia excesiva. Se trataba brutalmente a los reos con azotes y violencia sexual, se les negaba el alimento, se les sometía a trabajos forzados y se utilizaban sus cuerpos para experimentos médicos. En términos figurativos y literales, la prisión agotaba el cuerpo del prisionero. Esto se justificaba con argumentos sobre la incompetencia de los indígenas: la violencia corporal era necesaria al disciplinar no a sujetos racionales, sino a colectividades atadas por la tradición; de hecho, desde la india colonial hasta el Abu Ghraib contemporáneo se observa una relación mimética entre el barbarismo asumido de los sujetos coloniales-nativos y los actos de violencia y terror que se utilizan para contenerlos. La necesidad de violencia se justificó con argumentos sobre la cultura tradicional contra los derechos universales.

La disciplina en los penales fue una preocupación continua. El informe del Comité para la Disciplina en los Penales, de 1838, fue el antecedente de ejercicios relacionados en 1864, 1877, 1889, 1892 y 1919-1920. En ellos se pusieron sobre la mesa los temas de la higiene y el hacinamiento en los penales, esfuerzos por crear diferentes clases de prisioneros, intentos por segregar a las mujeres y por sustituir la mano de obra de los reos en obras públicas por trabajos intramuros. Sin embargo, más que un enfoque singular en su "contenido", la forma de estos recuentos resulta aleccionadora, pues aquí se encuentran en juego prácticas de "negación plausible". Estos registros de incriminación, obsesionados con visiones de un exceso de poder colonial, retratan a la autoridad imperial como una fuerza mejoradora, siempre responsable ante sus súbditos. ${ }^{9}$

${ }^{9}$ Casos de corrupción, tortura y negligencia burocrática iluminan la complicidad entre los regímenes coloniales y las entidades políticas liberales: cada uno se basó en una infraestructura de rendición de cuentas - la "cadena de mando"-que intentó restar 
En este contexto, Anand Yang ha explorado formas de resistencia contra la disciplina colonial. ${ }^{10}$ Yang argumenta que la diferencia social fuera de los muros de los penales (la casta, la religión) se reproducía dentro de las prisiones como un marcador de estatus que obraba en contra de los esfuerzos por homogeneizar su población. ${ }^{11}$ Las protestas en torno del "rancho" (la alimentación común) subrayaban la prominencia política de la comida. Las protestas en los penales desafiaron en última instancia la idea misma de la encarcelación: ${ }^{12}$ desde los esfuerzos por proteger la porosidad entre la vida dentro y fuera de la cárcel hasta el uso de la identidad social contra el anonimato de la disciplina colonial. ${ }^{13}$ Efectivamente, el capítulo de Yang nos muestra que los delincuentes politizaron precisamente aquellos aspectos de la vida diaria - los alimentos, los sanitarios y la indumentaria- a través de los cuales se les deshumanizaba. La respuesta colonial al delito político era diferente. Para la década de 1890 se deportaba a los presos políticos, especialmente aquellos que participaron en el "terror revolucionario". El movimiento Swadeshi, de 1905, atestiguó homicidios de funcionarios coloniales y ataques violentos contra la propiedad del gobierno. Posteriormente, se deportó a Bal Gangadhar Tilak a Mandalay, y a Veer Savarkar a Port Blair. Cada vez más,

importancia al exceso (pero implicarlo) individuándolo. Para consultar una exploración del liberalismo colonial y sus estructuras de negación plausible, véase Anupama Rao, "Problems of Violence, States of Terror: Torture in Colonial India", en Steven Pierce y Anupama Rao (eds.), Discipline and the Other Body: Correction, Corporeality, Colonialism, Durham, Duke University Press, 2006, pp. 151-185.

${ }^{10}$ Anand A. Yang, "Disciplining 'Natives': Prisons and Prisoners in Early Nineteenth Century India”, South Asia, vol. 10, núm. 2, 1987, pp. 29-45.

${ }^{11}$ Para consultar un importante ensayo sobre la segregación por género en el penal, véase Satadru Sen, "The Female Jails of Colonial India”, Indian Economic and Social History Review, vol. 39, núm. 4, 2002, pp. 417-438.

${ }^{12}$ Recordemos que en el periodo se había dado un gran cambio entre el castigo sin privación de la libertad y el que sí lo implicaba, marcado por el uso de metas, donde se mantenía a los acusados que se encontraban en juicio en la penitenciaría como sitio de corrección después de la sentencia condenatoria.

${ }^{13}$ Para consultar una brillante lectura antifoucaultiana sobre la resistencia popular al encarcelamiento, véase Peter Linebaugh, London Hanged: Crime and Civil Society in the Eighteenth Century, Cambridge, Cambridge University Press, 1993. Para consultar estudios subcontinentales recientes, véase la etnografía de un penal en Calcuta, de Mahua Bandhyopadhyaya, Everyday Life in a Prison: Confinement, Surveillance, Resistance, Hyderabad, Orient Blackswan, 2010, y el estudio clásico de Sumanta Banerjee, The Wicked City: Crime and Punishment in Calcutta, Hyderabad, Orient Blackswan, 2009. 
desde los terroristas revolucionarios hasta M. K. Gandhi, una estancia en prisión, el máximo símbolo de la ilegitimidad del poder colonial, se volvería un elemento de rigor para la vocación política de naturaleza nacionalista. ${ }^{14}$

A tono con estas consideraciones, David Arnold ha analizado la vida del nacionalista como preso político. ${ }^{15} \mathrm{~A}$ diferencia de los reos comunes, los presos políticos provenían de clases medias o altas, ${ }^{16}$ se les permitía acceso a periódicos, tinta y papel, y estaban alojados cerca los unos de los otros. Irónicamente, el género de "escritos de la cárcel”-memorias políticas, diarios, autobiografías, meditaciones sobre la cultura y la historia

${ }^{14}$ Además de estudios sobre individuos, desde M. N. Roy y Bhagat Singh hasta Subhas Chandra Bose y V. D. Savarkar, hay un gran cuerpo de estudios académicos sobre los movimientos Jugantar y Anushilan relacionados con el Swadeshi de Bengala; asimismo, existen valiosas ( $\mathrm{y}$ en aumento) obras sobre los itinerarios mundiales del terrorismo anticolonialista, con especial interés en las influencias de Mazzini y el movimiento Joven Italia, los Fenianos irlandeses, los anarquistas franceses, alemanes y rusos, y el Partido Ghadar en Estados Unidos. A pesar de sus ideologías políticas divergentes, sugieren un ámbito significativo, aunque subexplorado, del pensamiento y el activismo anticoloniales que ha tendido a verse oscurecido por la asociación del nacionalismo indio con la no violencia de Gandhi. Algunos estudios sobre tales ideologías y prácticas revolucionarias mundiales son los siguientes: C. A. Bayly, Recovering Liberties: Indian Thought in the Age of Liberalism and Empire, Cambridge, Cambridge University Press, 2012; Arun Coomer Bose, Indian Revolutionaries Abroad, 1905 1922: In the Background of International Developments, Patna, Bharati Bhawan, 1971; Sugata Bose y Kris Manjapra (eds.), Cosmopolitan Thought Zones: South Asia and the Global Circulation of Ideas, Nueva York, Palgrave Macmillan, 2010; Partha Chatterjee, "Terrorism: State Sovereignty and Militant Politics in India”, en Carol Gluck y Anne Loenhaupt Tsing (eds.), Words in Motion: Toward a Global Lexicon, Durham, Duke University Press, 2009, pp. 240-262; Isaac Land (ed.), Enemies of Humanity: The Nineteenth Century War on Terrorism, Nueva York, Palgrave Macmillan, 2008; Nicholas Owen, The British Left and India: Metropolitan Anti-Imperialism, 1885-1947, Oxford, Oxford University Press, 2007; Maia Ramnath, Haj to Utopia: How the Ghadar Movement Charted Global Radicalism and Attempted to Overthrow the British Empire, Berkeley, University of California Press, 2012; Tilak Raj Sareen, Indian Revolutionary Movement Abroad, 1905-1921, Nueva Delhi, Sterling, 1984; Michael Silvestri, Ireland and India: Nationalism, Empire and Memory, Nueva York, Palgrave Macmillan, 2009; Nico Slate, Colored Cosmopolitanism: The Shared Struggle for Freedom in the United States and India, Cambridge, Harvard University Press, 2012, y A. G. Noorani, Indian Political Trials, 1775-1947, Delhi, Oxford University Press, 2007.

${ }^{15}$ David Arnold, "The Self and the Cell: Indian Prison Narratives as Life Histories”, en David Arnold y Stuart Blackburn (eds.), Telling Lives in India: Biography, Autobiography and Life History, Indiana, Indiana University Press, 2004, pp. 29-53.

${ }^{16}$ Sobre el encarcelamiento de mujeres nacionalistas, véase Kamala Visweswaran, "Small Speeches, Subaltern Gender: Nationalist Ideology and Its Historiography", en Shahid Amin y Dipesh Chakrabarty (eds.), Subaltern Studies IX: Writings on South Asian History and Society, Nueva Delhi, Oxford University Press, 1996, pp. 83-125. 
indias- fue posible gracias a que la prisión colonial brindaba un espacio para la reflexión y un remanso de la agitación anticolonialista. Los nacionalistas de clase media experimentaron primero la vida en prisión con la intensificación del activismo anticolonial y muchos emprendieron prolongadas y amargas batallas para mejorar la vida en la penitenciaría. Sin embargo, Arnold nos recuerda que estaban familiarizados con la cárcel a través de la cultura literaria y popular, que representaban el penal como un lugar peligroso donde la jerarquía social era uniforme y la vulnerabilidad física aumentaba. El encarcelamiento de personas de la clase media normalizó la experiencia en prisión, pero también plantea preguntas sobre la fidelidad de la memoria. Por ejemplo, aunque estuvo en la cárcel en Sudáfrica entre 1908 y 1913, Gandhi escribió Satyagraba in South Africa en el penal de Yeravda en 1923 y $1924 .{ }^{17}$ Para entonces, su experiencia en prisión se había convertido en una narrativa de conversión sobre los beneficios de la austeridad en ese lugar. Como el asceta y el monje, el preso sufría un proceso de pérdida y recreación radicales del ser a través de la disciplina corporal: el sufrimiento humano era transformador, por lo que uno podía atestiguar cómo el cuerpo se consumía como signo de una transformación ética más profunda.

La obra de Raj Chandavarkar, que precede a las nociones sobre el carácter del sujeto resistente y el carácter del ser político dentro de los penales, ha desentrañado la espacialización del poder colonial en los escenarios urbanos de Bombay en el periodo de entreguerras. ${ }^{18}$ Sus análisis subrayan una institución social atrapada entre la autoridad burocrática colonial y el poder informal del vecindario. Chandavarkar argumenta que la liminalidad de la policía significó que podía ejercer su poder de manera arbitraria en contra de la gente y a la vez aliarse con

${ }^{17}$ Como se aclara posteriormente, no hemos incluido una discusión de la filosofía de Gandhi y sus consideraciones sobre la satyagraha o fuerza del alma no violenta, sus estudios sobre las tecnologías del ser ni trabajos sobre la protesta de Gandhi como práctica de la disciplina, sobre lo cual el texto clásico es quizás el de Ranajit Guha, "Discipline and Mobilize: Hegemony and Elite Control in Nationalist Campaigns", en Ranajit Guha, Dominance Without Hegemony: History and Power in Colonial India, Cambridge, Harvard University Press, 1997.

${ }^{18}$ Rajnarayan Chandavarkar, Imperial Power and Popular Politics: Class, Resistance and the State in India, C. 1850-1950, Cambridge, Cambridge University Press, 1998. 
ella contra el Estado y alentar "redes sociales informales [y] estructuras de poder locales”. Tales procesos de localización así como la estructura racializada de mando en el seno de la jerarquía policiaca produjeron el problema del "control policial sobre la policía”. ${ }^{19} \mathrm{Si}$ la diferencia colonial se convirtió en una coartada para el enfoque en el castigo más que en la rehabilitación, como indica Yang, también definió a la policía como representantes incómodos del poder, que estaban tanto dentro como fuera del Estado. ${ }^{20}$

\section{Legalidades e ilegalidades}

Durante su prolongada y accidentada trayectoria, la recaudación de rentas agrarias y el mantenimiento del orden público constituyeron, en conjunto, la piedra angular del interés del Estado colonial en India. ${ }^{21}$ El Estado colonial tuvo acceso a sus súbditos principalmente a través de redes ordenadas de relaciones de propiedad y los mecanismos del orden público, cada uno tocado por los anteriores intereses de los regímenes políticos indios en estos ámbitos. Con estas medidas también intentó contener y controlar, definir y disciplinar, y normalizar y naturalizar a los pueblos indios. Estas matrices enmarcaron y articularon nociones definidas de la persona y el súbdito, del indivi-

${ }^{19}$ David Arnold, Police Power and Colonial Rule in Madras, 1859-1947, Nueva Delhi, Oxford University Press, 1986.

${ }^{20}$ De hecho, los escritos de Chandavarkar sobre la cultura política de Bombay también constituyen una desviación importante para registrar las transformaciones infraestructurales del periodo de entreguerras, cuando el gobierno diárquico fomentó procesos de "localización" al delegar el poder sobre la educación, la higiene y la gobernanza municipal a las élites indígenas. Como es bien sabido, esta estructura de gobierno bifurcada racialmente produjo el "efecto" de un gobierno representativo, al tiempo que dejó a las autoridades provinciales sin la capacidad financiera para producir una legislación "mejoradora". El retiro putativo del Estado colonial y la regionalización del poder político amplió el campo de acción de las élites indígenas mientras que en última instancia las subordinó a la fuerza militar y a los poderes fiscales del Centro. No obstante, la localización (junto con los privilegios limitados que otorgaron las reformas de Montford de 1919) produjo una nueva política de la calle, el vecindario y la ciudad. El delito y el control policial desempeñaron un papel fundamental en este entorno en evolución.

${ }^{21}$ Esta sección se basa en argumentos iniciados en Saurabh Dube, Stitches on Time: Colonial Cultures and Postcolonial Tangles, Durham, Duke University Press, 2004. 
duo y la comunidad, inspirándose en esquemas “extranjeros” e "indígenas", así como en sus conjunciones.

En toda India, las variedades de acuerdos relativos a las rentas que establecieron los regímenes coloniales tendían a ver a las personas como parte de los arreglos de tenencia y propiedad, que dependían de las colectividades, en el orden agrario. En contraste, las imágenes que mediaban la noción de lo "individual” en los tribunales penales eran a la vez más claras y más complejas. Podría argumentarse que los procesos y los discursos de la ley moderna operaban con una noción heredada de "persona"; aquí se veía al individuo como un "todo" integrado, desprendible de la matriz de relaciones sociales y definible en términos de un conjunto de necesidades discreto. Dicha noción tiene un fuerte elemento normativo. Una construcción de regímenes modernos de poder es una manera de distinguir patologías, extender el control sobre ámbitos difusos e íntimos de la vida social y producir sujetos normalizados. Todos estos temas se exploraron anteriormente. Ahora el punto es que en maneras inherentemente diversas y accidentadas, los discursos y las prácticas que tal noción genera subyacen a la constitución del delito, la criminalidad y lo criminal según la ley colonial en el sur de Asia.

Sin embargo, al mismo tiempo esta noción heredada de la "persona" y la retórica asociada sobre el "Estado de derecho" se vieron comprometidas y calificadas de diversas maneras en la colonia india. Reiteramos esos tres sitios. En primer lugar estaban los temas intratables de la raza en escenarios legales, no sólo manifiestos como proposiciones del "retraso" de los nativos, sino subrayados especialmente en "asuntos" penales que implican la presencia conjunta de lo europeo y lo indio. En segundo lugar, en la producción de la figura del delincuente, en lugar de acceder exclusivamente a lo "individual", la ley colonial podía categorizar a una comunidad entera como una tribu-casta criminal. En sentidos inherentemente cargados de tensión, esto convertía a la comunidad a la vez en un individuo colectivo y en una colectividad individuada. Finalmente, el controvertido tema de los delitos "políticos" podía arrojar sus propias complejidades sobre la legitimidad del Estado, a la vez que revelaba variedades de contraideologías — desde el anti- 
colonialismo hasta el sindicalismo, desde el marxismo hasta el nacionalismo hindú- al promover nuevos repertorios de protesta pública en el siglo Xx.

Nada de esto debe sorprender. Después de todo, las autorrepresentaciones heroicas de la ley imperial estaban en tensión constante con la procuración rutinaria de la justicia colonial, y con frecuencia se veían excedidas por ella; de hecho, al determinar el delito y forjar al delincuente, la ley colonial solía ocuparse de entendimientos "indígenas", una y otra vez se basaba en los esquemas de rango y honor de las castas y las comunidades, y se valía incansablemente de las normas y las prácticas locales, todo ello para sus propios fines, desde luego. El establecimiento del delito y de construcciones de lo criminal en las prácticas y los discursos del derecho colonial-moderno fueron parte inexorable de los enredos imperiales y sus historias mutuas, que implican tanto a los colonizadores como a los colonizados.

La discusión de las legalidades-ilegalidades cotidianas, siempre junto a su interacción con la ley-la justicia del Estado, requiere que repensemos la figura del "criminal". Recordemos que de acuerdo con los dictados de la jurisprudencia colonial-moderna se cree que los intereses, las emociones y las motivaciones en una disputa, un conflicto o una violación a la ley emergen de los centros dinámicos de conciencia de los "individuos". Tal es la presunción de la ley; no obstante, al mismo tiempo las emociones, las motivaciones y los intereses que hay en juego en las controversias y los conflictos deben abordarse como elementos integrados de la experiencia social y las relaciones cotidianas; por tanto, los contornos de la experiencia resuenan con la fuerza de contingencias culturales y circunstancias críticas.

Además, al considerar las legalidades y las ilegalidades de los siglos XVIII al XXI, las diversas infracciones a la ley giraron en torno de relaciones de poder estructuradas por parentesco y género, por casta y comunidad y por edad y raza; matrices aparentemente "locales" pero sujetas a la autoridad gubernamental y la ley estatal de diversas maneras. Actuar de acuerdo con intereses-emociones y reparar problemas realizando actos de solidaridad o atacando al "enemigo" siempre ha significado negociar o reafirmar estas relaciones de poder variadas y difu- 
sas pero íntimas. ${ }^{22}$ Eso no es todo, pues tales represalias y solidaridades siempre se han visto alejadas de esa frase impresionante que invoca la ley, "un desliz momentáneo de la razón”. Más bien, de variadas formas, tales solidaridades y represalias resonaron con significados que apuntalan los objetos diarios y las convenciones cotidianas del orden social, apoyando y sustentando pero también contradiciendo y excediendo estas definiciones.

Por último, cabe destacar que los símbolos, las metáforas y las prácticas del derecho colonial-moderno no eran simplemente esquemas externos, retirados del mundo de los súbditos indios; más bien, tales esquemas formaron simultáneamente una legalidad extranjera, una estrategia de ajuste y venganza y un conjunto de recursos que los pueblos desplegaron de manera selectiva. Fue a través de tales medidas, superpuestas pero definidas, que los súbditos subcontinentales llegaron a definir nuevas patologías y a crear nuevas legalidades en el ámbito de la vida diaria, a la vez que interpretaban frescas formulaciones del orden en las comunidades. Una vez más, tales modalidades en la India imperial — que a la vez accedieron a la ley y la excedieron, sólo para fabricar nuevos significados para ella al tiempo que sucumbieron a sus seductivas estipulaciones- siguen encontrando configuraciones definidas en la poscolonia india.

Las consideraciones anteriores se han basado en los sucesos recientes de la antropología del derecho, que se han leído junto con la teoría social, el pensamiento crítico e historias imaginativas. Cuatro puntos destacan sobre la antropología jurídica, campo que no abordaremos en detalle. Primero, la división dominante en las consideraciones del derecho en la etnografía generalmente implicó un interés en las “reglas”, en contraposición con una expresión de los "procesos": mientras que las primeras buscaban análogos semejantes a la ley en todas las culturas, los últimos buscaron arraigar las legalidades y las ilegalidades en la resolución concreta de los procedimientos sociales. ${ }^{23} \mathrm{Se}$ -

\footnotetext{
${ }^{22}$ Este enemigo podría/puede ser, por ejemplo, un pariente, un vecino o el amante del cónyuge, una bruja o un chamán, el Estado moderno o el súbdito de clase baja.

${ }^{23}$ Véase, por ejemplo, John Comaroff y Simon Roberts, Rules and Processes: The Cultural Logic of Dispute in an African Context, Chicago, University of Chicago Press, 1981. Esta obra no sólo brinda un incisivo entendimiento del estado de la antropología
} 
gundo, estas tendencias, aparentemente distintas, podrían opacar la interacción crítica entre la práctica, el poder y el proceso para restringir el conflicto social a una expresión atenuada de localidad, como una unidad definida e innatamente "tradicional-local-consuetudinaria”. ${ }^{24}$ Tercero, esto es muy semejante a la manera en la que la oposición entre los procesos de debate

jurídica, desde el trabajo de Malinowski y Radcliffe-Brown hasta la década de 1970, sino que innova en la etnografía de las legalidades y las ilegalidades, especialmente, explora la dinámica entre la estructura social y la acción individual. Sin embargo, para consultar otras expresiones, anteriores a tales preguntas, véase Max Gluckman, Custom and Conflict in Africa, Londres, Basil Blackwell, 1955, y Max Gluckman, Judical Processes among the Barotse of Northern Nigeria, Manchester, Manchester University Press, 1955. Véase también Victor Turner, Schism and Continuity in an African Society: A Study of Ndembu Village Life, Oxford, Berg Publishers, 1996 (publicado originalmente en 1956). Algunos de los temas más amplios que están en juego en esta discusión se analizan en Saurabh Dube, "Anthropology, History, Historical Anthropology”, en Saurabh Dube (ed.), Historical Anthropology, Nueva Delhi, Oxford University Press, 2007, pp. 1-73.

${ }^{24}$ Esto se hace claro a partir del extenso estudio de Joan Vincent sobre la antropología jurídica, como parte de su notable análisis de la antropología, la política y la antropología política. Joan Vincent, Anthropology and Politics: Visions, Traditions, and Trends, Tucson, University of Arizona Press, 1990. También se subraya en June Starr y Jane Collier (eds.), History and Power in the Study of Law: New Directions in Legal Anthropology, Ithaca, Cornell University Press, 1988, y Sally Engle Merry, "Anthropology, Law, and Transnational Processes”, Annual Review of Anthropology, vol. 21, octubre de 1992, pp. 357-379. Véase también Laura Nader, Harmony Ideology: Justice and Control in a Zapotec Mountain Village, Stanford, Stanford University Press, 1991, y Comaroff y Roberts, Rules and Processes, op. cit. En el contexto de la antropología del sur de Asia, las cuestiones del conflicto y el poder con frecuencia encontraron expresiones bastante singulares e incluso curiosas a través de nociones de la "casta dominante" y de la "facción". Véase, por ejemplo, M. N. Srinivas, "The Dominant Caste in Rampura”, American Anthropologist, vol. 61, núm. 1, 1959, pp. 1-26; T. K. Oomen, "The Concept of Dominant Caste”, Contributions to Indian Sociology, vol. 4, núm. 1, 1970, pp. 73-83; M. N. Srinivas, Collected Essays, Nueva Delhi, Oxford University Press, 2002; Henry Orenstein, Gaon: Conflict and Cohesion in an Indian Village, Princeton, Princeton University Press, 1965; David Hardiman, "The Indian 'Faction': A Political Theory Examined”, en R. Guha (ed.), Subaltern Studies I: Writings on South Asian History and Society, Delhi, Oxford University Press, 1982; Oscar Lewis, Village Life in Northern India, Illinois, University of Illinois Press, 1958, y S. C. Dube, "Caste Dominance and Factionalism", Contributions to Indian Sociology, núm. 2, 1968, pp. 58-81. También véase Bernard S. Cohn, "Some Notes on Law and Change in North India", en Bernard S. Cohn, An Anthropologist among the Historians and Other Essays, Nueva York, Oxford University Press, 1990, pp. 554-574; Upendra Baxi, "Panchayat Justice: An Indian Experiment in Legal Access", en M. Cappelletti y B. Garth (eds.), From Access to Justice, vol. III: Emerging Issues and Perspectives, MilanAlphen aan den Rijn, Guiffre-Sijthoff y Noordhoff, 1979, pp. 341-386, y Robert M. Hayden, Disputes and Arguments amongst Nomads: A Caste Council in India, Nueva Delhi, Oxford University Press, 1999. 
tradicionales e inmutables y los sistemas de ley dinámicos y modernos gobernaron gran parte de lo escrito sobre el tema, incluido lo relativo al pluralismo jurídico. ${ }^{25}$ En cuarto y último lugar, a tono con transformaciones más amplias en la antropología, ahora se cuentan historias bastante diferentes sobre los enredos entre la ley estatal y las legalidades populares, lo (trans)nacional y lo local, la temporalidad y la espacialidad y la autoridad y la alteridad. ${ }^{26}$

Para infundir vida a tal multitud de consideraciones recurrimos a tres ejercicios recientes que discuten las legalidades y las ilegalidades. Cada uno de ellos rescata la figura de lo "criminal" y la forma del "crimen" de las determinaciones impersonales de la ley estatal. En lugar de abstracciones reificadas de la justicia colonial, se enfocan diversamente en el arraigo del delito y el delincuente en las relaciones diarias y las redes cotidianas de sentido y de poder, afectadas, respectivamente, por

${ }^{25}$ Esto lo aclara Sally Engle Merry, Colonizing Hawai' $i$ : The Cultural Power of Law, Princeton, Princeton University Press, 2000; Merry, "Anthropology, Law, and Transnational Processes", op. cit., y Starr y Collier (eds.), History and Power in the Study of Lare, op. cit. Véase también Patricia Ewick y Susan Silbey, The Common Place of Law: Stories from Everyday Life, Chicago, University of Chicago Press, 1998; Vincent, Anthropology and Politics, op. cit., y Pratiksha Baxi, "Feminist Contributions to Sociology of Law: A Review", Economic and Political Weekly, vol. XLIII, núm. 43, 2008, pp. 79-85.

${ }^{26}$ Sobre el sur de Asia véase, por ejemplo, Pratiksha Baxi, "Justice is a Secret: Compromise in Rape Trials", Contributions to Indian Sociology, vol. 44, núm. 3, octubre de 2010, pp. 207-233; Erin P. Moore, “Gender, Power, and Legal Pluralism”, American Ethnologist, vol. 20, núm. 3, 1993, pp. 522-542; Leela Dube, "Conflict and Compromise: Devolution and Disposal of Property in a Matrilineal Muslim Society", Economic and Political Weekly, vol. xxIx, núm. 21, 1994, pp. 1273-1284; Saurabh Dube, "Idioms of Authority and Engendered Agendas: The Satnami Mahasabha, Chhattisgarh, 1925-50", The Indian Economic and Social History Review, vol. 30, núm. 4, 1993, pp. 383-411; Ishita Banerjee Dube, "Taming Traditions: Legalities and Histories in Twentieth Century Orissa”, en Gautam Bhadra, Gyan Prakash y Susie Tharu (eds.), Subaltern Studies X: Writings on South Asian History and Society, Delhi, Oxford University Press, 1999, pp. 98-125, y Dube, Stitches of Time, op. cit. Véase también Upendra Baxi, “'The State's Emissary': The Place of Law in Subaltern Studies”, en Partha Chatterjee y Gyanendra Pandey (eds.), Subaltern Studies VII: Writings on South Asian History and Society, Delhi, Oxford University Press, 1992, pp. 257-264; Veena Das, "Subaltern as Perspective", en Ranajit Guha (ed.), Subaltern Studies vI: Writings on South Asian History and Society, Delhi, Oxford University Press, 1989, pp. 310-324; Saurabh Dube, Untouchable Pasts: Religion, Identity, and Authority among a Central Indian Community, 1780-1950, Albany, State University of New York Press, 1998, y Anupama Rao, The Caste Question: Dalits and the Politics of Modern India, Berkeley, University of California Press, 2009, especialmente los capítulos sobre la India poscolonial. 
la ley imperial y la autoridad gubernamental. Así, aquí se encuentran caminos rutinarios de legalidades e ilegalidades que tomaron forma a partir de la penuria y el hambre, del género y la sexualidad y de la casta y la comunidad.

Comencemos con el texto clásico de Ranajit Guha, Elementary Aspects of Peasant Insurgency in Colonial India. ${ }^{27}$ En el libro, el objetivo de Guha es situar al campesino como un sujetoagente político y consciente de la historia. Con este fin, analiza las rebeliones campesinas en el subcontinente a través del prolongado siglo XIX, para identificar las formas comunes y las ideas generales -o los “aspectos elementales"- de la insurgencia, la conciencia que dio forma a las actividades de los subalternos campesinos rebeldes. Entre las muchas aportaciones del trabajo de Guha al estudio del delito y la cultura, incluido el interés en los engranajes entre la pobreza y el crimen, la legalidad y la ilegalidad y la penuria y la rebeldía, apuntamos dos temas sobrepuestos: por un lado, los análisis y los intereses de Guha revelan posibilidades de expresiones más nuevas de legalidades e ilegalidades, tanto en la colonia como en la poscolonia; por el otro, al retratar al campesino insurgente como contemporáneo exacto del dominio colonial, enteramente coetáneo con él, Elementary Aspects apunta a la importancia de reflexionar sobre las dualidades jerárquicas generalizadas entre la tradición subalterna y la modernidad de la clase media. Ello acarrea una tremenda importancia para sondear críticamente las oposiciones que han caracterizado a los estudios históricos y antropológicos del delito y de la ley, los primeros obsesionados con el Estado colonial, y los segundos enamorados de la "tradición” india.

El segundo caso concierne al enfoque de Padma Anagol en la tendencia más amplia de humillar a las “mujeres delincuentes”. ${ }^{28}$ Ella plantea muchos casos de mujeres que habían sido violadas por familiares cercanos, especialmente sus cuñados; asimismo, ofrece ejemplos de mujeres de castas más bajas, desde Rakhuma, una jornalera que fuera víctima de violación en su camino a los arrozales y a quien después se acusó de infanticidio, hasta

${ }^{27}$ Ranajit Guha, Elementary Aspects of Peasant Insurgency in Colonial India, Delhi, Oxford University Press, 1983.

${ }^{28}$ Padma Anagol, The Emergence of Feminism in India, 1850-1920, Burlington, Ashgate Publishing Limited, 2005. 
una mujer mahar a quien su amante desalojó de su casa cuando quedó embarazada. En muchos casos, las mujeres que cometieron infanticidio fueron deportadas de por vida o enfrentaron encarcelamientos rigurosos, lo que desafiaba las suposiciones de la fragilidad y la debilidad de la mujer. Anagol argumenta que la criminalización de la mujer fue una respuesta a las ansiedades en torno de la libertad de la mujer, que comenzaron con el ascenso del activismo de las mujeres, desde la escritura de autobiografías hasta la demanda de derechos políticos. Sus exploraciones llaman la atención sobre las intersecciones entre el poder disciplinario del Estado (sobre todo la vigilancia de la reproducción de la mujer a través del sistema de registro de nacimientos y defunciones) y la moralidad de la comunidad, al tiempo que los funcionarios coloniales afirmaban constantemente que protegían a las mujeres de sus comunidades. Aquí se encuentra en juego la incómoda semejanza entre la violencia de la comunidad y la violencia del Estado.

El último ejemplo tiene que ver con la exploración, por uno de los autores del presente ensayo, de las intersecciones entre la ley colonial-estatal y las legalidades populares-contemporáneas. Aquí se encuentra un estudio basado en un raro y rico archivo de controversias aldeanas, cuyos juicios se llevaron a cabo en los escalafones más bajos de la jerarquía de las cortes imperiales. ${ }^{29}$ Dube trabaja en la brecha que hay entre los hechos limitados que se requieren para el juicio y la abundante información que brindan las declaraciones juradas. Esto posibilita analizar el juego entre las preocupaciones de las legalidades estatales ordenadas y los procesos de significación en el seno de las relaciones de la aldea. Así, el ensayo desafía la división insidiosa y hermética entre los procesos inmutables de debate, "tradicionales-folclóricos-populares", y los sistemas jurídicos dinámicos, "coloniales-modernos-estatales”, para revelar una interacción formidable de las normas cotidianas, los deseos familiares y las legalidades extranjeras. Por un lado, las imaginaciones y las acciones de la ley colonial se refractaron y se recrearon para definir nuevas patologías y fabricar legalidades nóveles en la vida cotidiana de las comunidades; por el otro la-

${ }^{29}$ Dube, Stitches on Time, op. cit. 
do, las nociones ya enmarcadas de delito y emoción, de la propiedad y la persona en el discurso y la práctica de la ley moderna recibieron la influencia callada de la presencia recalcitrante de las "costumbres" y las "tradiciones" de los nativos, las prácticas no sancionadas de los sujetos subalternos.

\section{Predilecciones poscoloniales}

El periodo poscolonial presenta un problema para nuestros esfuerzos. No es sólo que los términos y las transformaciones del delito, la violencia y la ley en la India independiente constituyan temas complejos y vastos, sino que también hay diversas maneras de abordar y explorar estas cuestiones sobre las transformaciones contemporáneas del Estado y la sociedad. Todo lo que se asemeje a un escrutinio global de tales temas es ajeno al alcance de este ensayo. Más adelante brindamos un recuento esquemático de sucesos críticos y transformaciones de política y evaluamos su efecto sobre la ley, el delito y la vida diaria en la poscolonia.

Recuérdese ahora que el anticolonialismo cuestionó la "legalidad" del gobierno colonial y buscó volver ingobernable el subcontinente a través de la acción colectiva: la agitación popular y la política de la calle se plantearon contra la ilegitimidad de la ley colonial. Los años anteriores a la Partición y la independencia fueron testigos de la violencia contra el Estado acompañada de la violencia entre comunidades religiosas. Esto produjo el problema de rendir cuentas por la violencia masiva y la falta de mecanismos legales a través de los cuales perseguir a los delincuentes, fueran hindúes o musulmanes. Así, los académicos especialistas en la Partición se han centrado en la cuestión de cómo las comunidades sobreviven a las secuelas del trauma histórico cuando enfrentan la falta de reparación de los daños. ${ }^{30}$

${ }^{30}$ Existe un cuerpo de literatura nutrido y creciente sobre la Partición, desde el enfoque de la historia política hasta las memorias personales. Una pequeña muestra del tipo de trabajo que tenemos en mente incluye: Urvashi Butalia, The Other Side of Silence: Voices from the Partition of India, Nueva Delhi, Penguin Books India, 1998; Veena Das, Life and Words; Violence and the Descent into the Ordinary, Berkeley, University of California Press, 2006; Ritu Menon y Kamla Bhasin, Borders and Boundaries: Women in India's Partition, New Brunswick, Rutgers University Press, 1998; Gyanendra 


\section{El periodo posterior a 1947 ha atestiguado dos tendencias distintivas y aparentemente divergentes. Por un lado vemos la desmovilización exitosa del activismo popular a través de la institución de las protecciones y las salvaguardas constitucio- nales. ${ }^{31}$ Así, la protección jurídica contra los delitos sociales, tales como la práctica de la intocabilidad y la violencia contra la mujer, es un hecho social importante del paisaje poscolonial indio. ${ }^{32}$ La región ha atestiguado simultáneamente una creciente}

Pandey, Remembering Partition: Violence, Nationalism and History in India, Cambridge, Cambridge University Press, 2002; Vazira Fazila-Yacoobali Zamindar, The Long Partition and the Making of Modern South Asia: Refugees, Boundaries, Histories, Nueva York, Columbia University Press, 2007.

${ }^{31}$ Cabe destacar que existen numerosos estudios históricos que relacionan la Constitución india con la Ley del Gobierno de India, de 1935. Asimismo, existe una vasta literatura jurisprudencial sobre las ideas de los derechos y los deberes según se expresaban en la Constitución india, estudios sobre la relación entre los tribunales altos y los inferiores, consideraciones sobre la balanza de poder cambiante entre el ejecutivo y el judicial, y estudios de formas cuasi jurídicas como los Comités de Investigación que se crearon tras la revelación de fraudes políticos y económicos o de violencia sociopolítica a gran escala como los motines comunitarios. Conocemos la existencia de estos estudios, incluido especialmente su potencial para involucrar cuestiones del delito y la legalidad poscolonial desde otros ángulos, pero no es posible analizarlos en el presente artículo.

${ }^{32}$ Como sabemos, la casta, que se encuentra en el centro de los compromisos constitucionales con la justicia social, se convirtió en un indicador "semejante a la clase" de privación socioeconómica que requería acción afirmativa. Mientras tanto, la intocabilidad se abolió y se criminalizó su práctica y a sus practicantes. Para consultar una discusión sobre la relación entre la casta y las políticas de acción afirmativa en la India posindependiente, véase Marc Galanter, Competing Equalities: Law and the Backward Classes in India, Delhi, Oxford University Press, 1984. El siguiente vínculo incluye una lista completa de los prolongados y sostenidos abordajes de Galanter sobre la práctica y la historia del derecho indio: [marcgalanter.net/cv.htm].

Los temas de género conllevan sus propias complejidades, sobre todo porque atañen directamente a los vínculos entre comunidad e identidad así como a la relación entre comunidad y Estado. Las leyes personales se diferencian por comunidad religiosa y gobiernan la práctica del matrimonio, el divorcio, el sustento y la adopción para cada una de estas comunidades. (Cuando la conversión no es un problema, los matrimonios interreligiosos entran en el ámbito de la Ley de Matrimonios Especiales de 1954, que reemplazó a la Ley anterior, de 1872.) En el siglo xx, la Ley sobre la Shari'a, de 1937, y la aprobación de la Ley de disolución de matrimonios musulmanes de 1939, así como la reforma fragmentaria de la ley personal hindú en la década de 1950, que comenzó con la aprobación de la Ley de matrimonio hindú de 1955, buscó eliminar las diferencias tradicionales y sectarias dentro de estas comunidades, con el fin de codificar la ley personal para estos grupos religiosos. En fechas más recientes, las comunidades minoritarias, especialmente los musulmanes, han encontrado que la identidad de la comunidad se ve desafiada (y afirmada) en torno de crisis que tienen que ver con los "derechos de la mujer". En relación con el tema de los derechos de las mujeres musulmanas, incluida una discusión sobre cómo éstos se han constituido 
militarización del Estado, el gobierno mediante la invocación de leyes excepcionales y la influencia creciente del secesionismo político y la violencia paraestatal. ${ }^{33}$

Una manera de explicar estos procesos es ubicarlos en el periodo transformador que fue la década de 1970, cuando el proyecto de islamización de Zia ul-Haq, en Pakistán, coincidió con la declaratoria de Emergencia Nacional en India, por Indira Gandhi (1975-1977). Cada uno de ellos permitió la entrada de nuevos actores políticos al escenario nacional, ya fuera el ascenso de lo que comúnmente se denomina el "islam político" en Pakistán o las fuerzas anticongreso, como el partido Janata (que incluyó al Jana Sangh), en India. Los sindicatos y la movilización de las mujeres parecen haber sufrido un golpe decisivo en Pakistán. ${ }^{34}$ En India, el periodo posterior a la Emergencia atestiguó el ascenso de los esfuerzos de la gente que no pertenecía a un partido, así como el ascenso de un movimiento en pro de las libertades civiles que defendió temas de la violencia del

históricamente en oposición a los derechos de las mujeres hindúes de castas altas, véase: Flavia Agnes, Law and Gender Inequality: The Politics of Women's Rights in India, Delhi, Oxford University Press, 1999; Mary E. John, "Alternate Modernities? Reservations and Women's Movement in $20^{\text {th }}$ Century India", Economic and Political Weekly, vol. 35, núm. 43-44, 2000, pp. 3822-3829; Nivedita Menon, "State/Gender/Community: Citizenship in Contemporary India", Economic and Political Weekly, vol. 33, núm. 5, enero de 1998, pp. PE3-PE10; Mrinalini Sinha, Specters of Mother India: The Global Restructuring of an Empire, Durham, Duke University Press, 2006; Rajeswari Sunder Rajan, "Shah Bano", Signs: Journal of Women in Culture and Society, vol. 14, núm. 3, 1989, pp. 558-582; Rajeswari Sunder Rajan, “The Ameena 'Case': The Female Citizen and Subject", en Rajeswari Sunder Rajan, The Scandal of the State: Women, Law and Citizenship in Postcolonial India, Durham, Duke University Press, 2003, pp. 41-71. Para consultar estudios sobre los derechos de las minorías tal como aparecen en la Constitución en términos más generales, véase Shefali Jha, "Secularism in the Constituent Assembly Debates, 1946-1950", Economic and Political Weekly, vol. 37, núm. 30, 2002, pp. 3175-3180; Neera Chandoke, Beyond Secularism: The Rights of Religious Minorities, Delhi, Oxford University Press, 1999; Ralph Retzlaff, "The Problem of Communal Minorities in the Drafting of the Indian Constitution”, en R. N. Spann (ed.), Constitutionalism in Asia, Londres, Asia Publishing House, 1963.

${ }^{33}$ Véase, por ejemplo, Ujwal Kumar Singh, The State, Democracy, and Anti-Terror Laws, Nueva Delhi, Sage, 2007.

${ }^{34}$ Véase Asma Jahangir y Hina Jillani, The Hudood Ordinances: A Divine Sanction? A Research Study of the Hudood Ordinances and their Effect on the Disadvantaged Sections of Pakistan Society, Lahore, Rohtas Books, 1990; Ayesha Jalal, "The Convenience of Subservience", en Denis Kandiyoti (ed.), Women, Islam and the State, Londres, Macmillan, 1991, pp. 77-114; Ian Talbot, Pakistan: A Modern History, Londres, Hurst, 2009, y Saadi Toor, The State of Islam: Culture and Cold War Politics in Pakistan, LondresNueva York, Pluto Press, 2011. 
Estado, desde la muerte en prisión hasta la masacre de civiles en manos del ejército. ${ }^{35}$

Ahora, los movimientos populares en India han subrayado la contradicción entre la democracia popular y las fuerzas estatales de diversas maneras, entre las que se encuentran las luchas contra el desplazamiento masivo para la construcción de infraestructura estatal (de lo cual el ejemplo mejor conocido es quizás el de Narmada Bachao Andolan); las demandas de justicia, en foros nacionales e internacionales, de las víctimas del desastre de Union Carbide, en Bhopal; las exigencias de los dalit de que se reconozca la discriminación de castas internacionalmente; las luchas urbanas contra la demolición y el desalojo de inmuebles en casi todas las ciudades indias hoy en día; las batallas legales por la despenalización de la homosexualidad; el reconocimiento del trabajo sexual como mano de obra, y los esfuerzos de comunidades adivasi politizadas por desafiar patrones de acumulación agresiva de las industrias estatal y privada en las regiones de la India media, ricas en minerales. Estas luchas, muchas auxiliadas por el ascenso del litigio de interés público y la intervención de abogados progresistas, han expandido el ámbito del activismo legal e imputado al Estado crímenes contra el pueblo. ${ }^{36}$ Aunque las fuerzas estatales con frecuencia logran aplastar las iniciativas populares, las legalidades alternativas siguen siendo una fuerza potente para desafiar las políticas antipopulares del Estado indio.

Un último y notable conjunto de transformaciones contemporáneas concierne a los efectos de la reforma neoliberal

${ }^{35}$ Considérense los informes de determinación de los hechos de la Unión de los Pueblos por los Derechos Democráticos (Delhi), las notables actividades del Comité de Libertades Civiles de Andhra Pradesh, los escritos y el activismo del miembro de dicho comité, más adelante fundador del Foro de Derechos Humanos, K. Balagopal [balagopal.org/]. También considérese Ujwal Kumar Singh, Political Prisoners in India, Delhi, Oxford University Press, 2001.

${ }^{36}$ En este sentido cabe pensar en la obra de un académico que consideramos el fundador de los estudios jurídicos críticos en India, Upendra Baxi [upendrabaxi.net/ documents.html], los escritos del especialista en estudios jurídicos Rajeev Dhavan y los trabajos del Colectivo de Abogados y de algunos de los abogados relacionados con esta iniciativa a lo largo de los años, incluidos Indira Jaisingh, Colin Gonsalves y Mihir Desai. El campo contemporáneo del activismo legal, incluido el giro hacia las leyes internacionales de derechos humanos, sucede a este primer momento, que surgió de las experiencias de la Emergencia y de Naxalbari en la década de 1970. 
promercado en la gobernanza legal. ${ }^{37}$ Las clases medias de India (término que, cabe destacar, es una categoría aspiracional más que un descriptor de la realidad social) parecen estar retirándose de la sociedad a sus enclaves privatizados, a la vez que propugnan su apoyo a las políticas contra los pobres, como el desalojo de los barrios marginales, las medidas contra los vendedores ambulantes y la zonificación residencial para parques y áreas verdes. ${ }^{38} \mathrm{Al}$ mismo tiempo, los cambios en el campo, como la contracción del acceso de los agricultores al crédito y la invasión de tierras para la creación de zonas económicas especiales (ZEE) están haciendo que la agricultura deje de ser viable a la vez que empuja a gran número de emigrantes a las zonas urbanas. Estas comunidades en crisis buscan refugio en economías ilícitas o subterráneas y una existencia criminalizada, pero también se organizan en torno de identidades religiosas y étnicas que se han vuelto potentes espacios de conflicto violento.

Una vez más proporcionamos tres ejemplos que reflexionan sobre la coexistencia contradictoria de la protección estatal y la culpabilidad del Estado en el periodo poscolonial. Todos estos esfuerzos exploran cómo las determinaciones impersonales de la ley, ahora con sus proyecciones claramente expresadas del ciudadano influido por la casta y el sujeto con género (así como su dependencia tácita de las divisiones entre la "mayoría” y la "minoría"), siguen produciendo nuevas paradojas para la procuración de justicia en la India contemporánea. Es decir,

${ }^{37}$ Con base en la descripción que hace Sudipta Kaviraj en cuanto a que la transición poscolonial muestra la lógica de la "revolución pasiva", Partha Chatterjee ha argumentado que el neoliberalismo indio está marcado por divisiones entre la sociedad "civil" y la "política". Además, Chatterjee utiliza la teorización del economista Kalyan Sanyal de la "acumulación primitiva" para abordar las transformaciones de la economía política en este periodo. Véase Partha Chatterjee, "Classes, Capital and Indian Democracy", Economic and Political Weekly, vol. xLIII, núm. 46, noviembre de 2008, pp. 89-93; Sudipta Kaviraj, "A Critique of Passive Revolution”, Economic and Political Weekly, vol. xxIII, núm. 45-47, noviembre de 1988, pp. 2429-2433, 2436-2441 y 24432444, y Kalyan Sanyal, Rethinking Capitalist Development: Primitive Accumulation, Governmentality, and Postcolonial Capitalism, Delhi, Routledge, 2007.

${ }^{38}$ Existen numerosos estudios sobre la nueva política de las clases medias urbanas en India. Sobre Delhi y Mumbai, respectivamente, véase, por ejemplo, Amita Baviskar, "Urban Exclusions: Public Spaces and the Poor in Delhi", en Bharati Chaturvedi (ed.), Finding Delhi: Loss and Renerval in a Megacity, Nueva Delhi, Penguin, pp. 3-15, y Arvind Rajagopal, "The Violence of Commodity Aesthetics: Hawkers, Demolition Raids, and a New Regime of Consumption”, Social Text, vol. 19, núm. 3(68), pp. 91-113. 
estos tres ejemplos revelan las intimidades peculiares entre las comunidades vulnerables - los dalit, los musulmanes y las mujeres-y el Estado poscolonial, para subrayar la importancia de la ley y el delito como ámbitos clave del involucramiento político entre los ciudadanos y el Estado.

Anupama Rao ha abordado la reinscripción de la vulnerabilidad de los dalit a través de las mismas leyes y disposiciones constitucionales que tienen como objetivo proteger a los dalit de la violencia de las castas superiores. ${ }^{39} \mathrm{Al}$ analizar un caso de "atrocidad de castas", el homicidio de un kotwal dalit en la escalinata de un templo Hanuman en la zona rural de Maharashtra en 1991, Rao incursiona en la forma inesperada en que las leyes estrictas, como la Ley de prevención de atrocidades, de 1989, pueden volverse inútiles. En él, la autora se concentra en dos aspectos del fracaso judicial en la protección de los dalit. El primero implica las alianzas locales, que permiten el encubrimiento policial y el mal manejo burocrático. El segundo involucra, más significativamente, una contradicción en la expresión de las leyes contra las atrocidades. Este último asume el funcionamiento de una conciencia de casta colectiva como la "causa" detrás de la violencia contra los dalit, aunque los casos de atrocidades se adjudican como cualquier otro asunto, es decir, a través de la individuación del delito. Rao argumenta que la contradicción entre la causa colectiva y el castigo individuado reproduce el estatus excepcional de los dalit como sujetos-ciudadanos vulnerables y en riesgo.

En el segundo ejemplo, Rajeswari Sunder Rajan se ha concentrado en Phoolan Devi (la reina bandida) y en su rendición para desafiar las representaciones comunes de la vulnerabilidad femenina, especialmente al analizar el poder de la mujer proscrita en sus negociaciones con el Estado poscolonial. ${ }^{40}$ Cuando Phoolan Devi justificó su recurso al bandidaje como una forma de venganza por la violencia de las castas superiores contra las inferiores, en particular contra las mujeres de estas

${ }^{39}$ Anupama Rao, "Death of a Kotwal: Injury and the Politics of Recognition", en Shail Mayaram, M. S. S. Pandian y Ajay Skaria (eds.), Subaltern Studies XII, Nueva Delhi, Permanent Black-Ravi Dayad Publisher, 2005, pp. 140-187.

${ }^{40}$ Rajeswari Sunder Rajan, The Scandal of the State: Women, Law and Citizenship in Postcolonial India, Durham, Duke University Press, 2003. 
comunidades, ella expresó una narrativa que guardaba semejanzas sorprendentes con los paradigmas modernos tempranos del castigo descentralizado. Aquí, Sunder Rajan nota la equivalencia entre la exclusión estructural por las élites de las castas y el Estado, por un lado, y la generación de un reinado de terror a manos de los dacoits mediante el uso de la violencia dirigida en el valle de Chambal, por el otro. El último utiliza un modelo de justicia popular que resulta profundamente perturbador, porque desafía explícitamente el derecho exclusivo del Estado sobre el castigo a través del recurso de la venganza popular. En el caso de la rendición negociada de Phoolan Devi, sucede además que su género se ignoró y se sobresimbolizó a la vez, lo cual indicó la dificultad de aprehender a la proscrita como una "mujer asesina" más que como el sujeto muerto o moribundo.

He aquí el último ejemplo. Tanika Sarkar ha abordado el isomorfismo de la mujer con la comunidad con el fin de analizar la política de la muerte o la lógica necropolítica de los pogromos de Gujarat, en 2002. ${ }^{41}$ Mediante el reportaje crítico, el análisis académico y una sensibilidad literaria, su obra subraya la importancia de la violencia sexual al centrarse en cómo se utilizaron, se mutilaron y se descartaron los cuerpos de las mujeres durante la matanza en el oeste de India. Sarkar argumenta que las formas y las lógicas simbólicas de la violencia expresaron fantasías escalofriantes de venganza hindú y aniquilación histórica del otro musulmán. Aquí, la intimidad de la violencia sexual, como una forma de terror dotada de género específicamente, fue una violación a la comunidad musulmana.

Como han anotado otros autores, el carácter de Gujarat como un "milagro" del desarrollo depende de su profunda historia de división comunal, expropiación de propiedades de los musulmanes y su exclusión de la vida pública en el Estado. Así, el neoliberalismo brinda un encubrimiento efectivo a los intentos de limpieza étnica. ${ }^{42}$ En este escenario, los intereses de Sar-

${ }^{41}$ Tanika Sarkar, "Semiotics of Terror: Muslim Children and Women in Hindu Rashtra", Economic and Political Weekly, vol. 37, núm. 28, 2002, pp. 2872-2876.

${ }^{42}$ V'éase Nalin Mehta y Mona G. Mehta (eds.), Gujarat Beyond Gandhi, Identity, Conflict and Society, número especial de South Asian History and Culture, vol. 1, núm. 4, octubre de 2010. También véase el estudio reciente sobre la segregación espacial de los musulmanes en la India urbana: Laurent Gayer y Christophe Jaffrelot (eds.), Muslims in Indian Cities: Trajectories of Marginalization, Londres, Hurst and Co., 2012. 
kar nos permiten marcar un conjunto más amplio de cambios críticos en el delito, la ley y la política en la India contemporánea. ${ }^{43}$ Ahora, nuevos repertorios de crimen, incluidos los perpetrados por funcionarios estatales, son reivindicaciones nuevas a la visibilidad pública $-y$, por tanto, también demandas de reconocimiento social- así como indicadores de transformaciones más profundas de la política poscolonial. Cada vez más, los espectáculos de violencia y delito son, en sí mismos, sitios de política y gobernanza, más que sólo el exceso aberrante de esta última.

\section{Traducción del inglés: María Capetillo}

Dirección institucional de los autores:

Saurabh Dube

Centro de Estudios de Asia y África

El Colegio de México

Camino al Ajusco 20

Pedregal de Sta. Teresa

México, D.F., 10740

$\triangle$ sdube@colmex.mx

Anupama Rao

Barnard College

Columbia University

3009 Broadway

New York, NY, 10027

\arao@barnard.edu

${ }^{43}$ Es el caso, especialmente debido a la centralidad geopolítica del sur de Asia, para la guerra contra el terrorismo emprendida por Estados Unidos. Sobre este tema, cabe mencionar el reportaje, sensible políticamente, de Ahmed Rashid, al igual que las provocaciones teóricas en Faisal Devji, Landscapes of the Jihad: Militancy, Morality, Modernity, Cornell, Cornell University Press, 2005. La coyuntura actual también ilustra el efecto local de preocupaciones mundiales sobre el "terror musulmán"; por ejemplo, en relación con la migración de bangladeshíes pobres a India, o con la politización de los derechos de la mujer musulmana en la región. Como sabemos, tales intervenciones surgen desde discursos de derechos mundiales que afirman "salvar" a la mujer musulmana, hasta delitos de honor y disciplina pública que emplean el cuerpo de la mujer como sitio performativo para representar ansiedades en torno del estatus social, la identidad comunitaria y el privilegio masculino. 


\section{Bibliografía}

Adiga, Aravind, The White Tiger, Nueva York, Free Press, 2008.

Agnes, Flavia, Law and Gender Inequality: The Politics of Women's Rights in India, Nueva Delhi, Oxford University Press, 1999.

Anagol, Padma, The Emergence of Feminism in India, 1850-1920, Burlington, Ashgate Publishing Limited, 2005.

Anderson, Clare, Convicts in the Indian Ocean: Transportation from South Asia to Mauritius, 1815-53, Londres, Macmillan, 2000.

Appadurai, Arjun, "Spectral Housing and Ethnic Cleansing: Notes on Millennial Mumbai”, Public Culture, vol. 12, núm. 3, 2000, pp. 627-651.

Arnold, David, Police Power and Colonial Rule in Madras, 1859-1947,

Nueva Delhi, Oxford University Press, 1986.

Arnold, David, "The Self and the Cell: Indian Prison Narratives as Life Histories", en David Arnold y Stuart Blackburn (eds.), Telling Lives in India: Biography, Autobiography and Life History, Indiana, Indiana University Press, 2004, pp. 29-53.

Asad, Talal, "On Torture, or Cruel, Inhuman, and Degrading Treatment", en Arthur Kleinman, Veena Das y Margaret Lock (eds.), Social Suffering, Delhi, Oxford University Press, 1998, pp. 285-308.

Bandhyopadhyaya, Mahua, Everyday Life in a Prison: Confinement, Surveillance, Resistance, Hyderabad, Orient Blackswan, 2010.

Banerjee, Sumanta, The Wicked City: Crime and Punishment in Calcutta, Hyderabad, Orient Blackswan, 2009.

BANERJEE DuBE, Ishita, "Taming Traditions: Legalities and Histories in Twentieth Century Orissa", en Gautam Bhadra, Gyan Prakash y Susie Tharu (eds.), Subaltern Studies X: Writings on South Asian History and Society, Delhi, Oxford University Press, 1999, pp. 98-125.

Baviskar, Amita, "Urban Exclusions: Public Spaces and the Poor in Delhi", en Bharati Chaturvedi (ed.), Finding Delhi: Loss and Renewal in a Megacity, Nueva Delhi, Penguin, pp. 3-15.

BAXI, Pratiksha, "Feminist Contributions to Sociology of Law: A Review", Economic and Political Weekly, vol. XLIII, núm. 43, 2008, pp. 79-85.

BAXI, Pratiksha, "Justice is a Secret: Compromise in Rape Trials", Contributions to Indian Sociology, vol. 44, núm. 3, octubre de 2010, pp. 207-233.

BAXI, Upendra y M. Galanter, "Panchayat Justice: An Indian Experiment in Legal Access", en M. Cappelletti y B. Garth (eds.), From Access to Justice, vol. III: Emerging Issues and Perspectives, Mi- 
lan-Alphen aan den Rijn, Guiffre-Sijthoff y Noordhoff, 1979, pp. 341-386.

BaxI, Upendra, “'The State's Emissary': The Place of Law in Subaltern Studies", en Partha Chatterjee y Gyanendra Pandey (eds.), Subaltern Studies VII: Writings on South Asian History and Society, Delhi, Oxford University Press, 1993, pp. 257-264.

BAYLY, C. A., Recovering Liberties: Indian Thought in the Age of Liberalism and Empire, Cambridge, Cambridge University Press, 2012.

Bose, Arun Coomer, Indian Revolutionaries Abroad, 1905-1922: In the Background of International Developments, Patna, Bharati Bhawan, 1971.

Bose, Sugata y Kris Manjapra (eds.), Cosmopolitan Thought Zones: South Asia and the Global Circulation of Ideas, Nueva York, Palgrave Macmillan, 2010.

Butalia, Urvashi, The Other Side of Silence: Voices from the Partition of India, Nueva Delhi, Penguin Books India, 1998.

Chandavarkar, Rajnarayan, Imperial Power and Popular Politics: Class, Resistance and the State in India, C. 1850-1950, Cambridge, Cambridge University Press, 1998.

Chandoke, Neera, Beyond Secularism: The Rights of Religious Minorities, Delhi, Oxford University Press, 1999.

Chatterjee, Partha, "Classes, Capital and Indian Democracy", Economic and Political Weekly, vol. XLIII, núm. 46, noviembre de 2008, pp. 89-93.

Chatterjee, Partha, "Terrorism: State Sovereignty and Militant Politics in India”, en Carol Gluck y Anne Loenhaupt Tsing (eds.), Words in Motion: Toward a Global Lexicon, Durham, Duke University Press, 2009, pp. 240-262.

CoHN, Bernard S., "Some Notes on Law and Change in North India", en Bernard S. Cohn, An Anthropologist among the Historians and Other Essays, Nueva York, Oxford University Press, 1990, pp. 554-574.

Comaroff, John y Simon Roberts, Rules and Processes: The Cultural Logic of Dispute in an African Context, Chicago, University of Chicago Press, 1981.

DAs, Veena, Life and Words; Violence and the Descent into the Ordinary, Berkeley, University of California Press, 2006.

Das, Veena, "Subaltern as Perspective", en Ranajit Guha (ed.), Subaltern Studies VI: Writings on South Asian History and Society, Delhi, Oxford University Press, 1989, pp. 310-324.

DevjI, Faisal, Landscapes of the Jihad: Militancy, Morality, Modernity, Cornell, Cornell University Press, 2005. 
DubE, Leela, "Conflict and Compromise: Devolution and Disposal of Property in a Matrilineal Muslim Society", Economic and Political Weekly, vol. xxix, núm. 21, 1994, pp. 1273-1284.

Dube, Saurabh, "Anthropology, History, Historical Anthropology", en Saurabh Dube (ed.), Historical Anthropology, Nueva Delhi, Oxford University Press, 2007, pp. 1-73.

DuBE, Saurabh, "Idioms of Authority and Engendered Agendas: The Satnami Mahasabha, Chhattisgarh, 1925-50", The Indian Economic and Social History Reviere, vol. 30, núm. 4, 1993, pp. 383-411.

Dube, Saurabh, Stitches on Time: Colonial Cultures and Postcolonial Tangles, Durham, Duke University Press, 2004.

Dube, Saurabh, Untouchable Pasts: Religion, Identity, and Authority among a Central Indian Community, 1780-1950, Albany, State University of New York Press, 1998.

Dube, S. C., "Caste Dominance and Factionalism", Contributions to Indian Sociology, núm. 2, 1968, pp. 58-81.

EwIck, Patricia y Susan Silbey, The Common Place of Law: Stories from Everyday Life, Chicago, University of Chicago Press, 1998.

Foucault, Michel, Discipline and Punish, Nueva York, Vintage Books, 1995.

GaLANTER, Marc, Competing Equalities: Law and the Backward Classes in India, Delhi, Oxford University Press, 1984.

GAYER, Laurent y Christophe Jaffrelot (eds.), Muslims in Indian Cities: Trajectories of Marginalization, Londres, Hurst and Co., 2012.

Gluckman, Max, Custom and Conflict in Africa, Londres, Basil Blackwell, 1955.

Gluckman, Max, Judical Processes among the Barotse of Northern Nigeria, Manchester, Manchester University Press, 1955.

GuHA, Ranajit, "Discipline and Mobilize: Hegemony and Elite Control in Nationalist Campaigns", en Ranajit Guha, Dominance without Hegemony: History and Power in Colonial India, Cambridge, Harvard University Press, 1997.

GuHA, Ranajit, Elementary Aspects of Peasant Insurgency in Colonial India, Delhi, Oxford University Press, 1983.

Hardiman, David, “The Indian 'Faction': A Political Theory Examined", en R. Guha (ed.), Subaltern Studies I: Writings on South Asian History and Society, Delhi, Oxford University Press, 1982. HaYden, Robert M., Disputes and Arguments amongst Nomads: A Caste Council in India, Nueva Delhi, Oxford University Press, 1999. IgnatiefF, Michael, A Just Measure of Pain: The Penitentiary in the Industrial Revolution 1750-1850, Nueva York, Pantheon Books, 1978. 
JahangIR, Asma y Hina Jillani, The Hudood Ordinances: A Divine Sanction? A Research Study of the Hudood Ordinances and their Effect on the Disadvantaged Sections of Pakistan Society, Lahore, Rohtas Books, 1990.

Jalal, Ayesh, "The Convenience of Subservience", en Denis Kandiyoti (ed.), Women, Islam and the State, Londres, Macmillan, 1991, pp. 77-114.

JHA, Shefali, "Secularism in the Constituent Assembly Debates, 1946-1950", Economic and Political Weekly, vol. 37, núm. 30, 2002, pp. 3175-3180.

JoHn, Mary E., “Alternate Modernities? Reservations and Women's Movement in $20^{\text {th }}$ Century India", Economic and Political Weekly, vol. 35, núm. 43-44, 2000, pp. 3822-3829.

JosHi, Chitra, "Fettered Bodies: Labouring on Public Works in Nineteenth Century India", en Marcel van der Linden y Prabhu Mohapatra (eds.), Labour Matters: Towards Global Histories, Nueva Delhi, Tulika Books, 2009, pp. 3-21.

Kaviraj, Sudipta, "A Critique of Passive Revolution", Economic and Political Weekly, vol. xxIII, núm. 45-47, noviembre de 1988, pp. 2429-2433, 2436-2441 y 2443-2444.

KaviRAJ, Sudipta, "Reading a Song of the City: Images of the City in Literature and Films”, en Preben Kaarsholm (ed.), City Flicks: Indian Cinema and the Urban Experience, Calcuta, Seagull Books, 2004, pp. 60-82.

Land, Isaac (ed.), Enemies of Humanity: The Nineteenth Century War on Terrorism, Nueva York, Palgrave Macmillan, 2008.

LewIs, Oscar, Village Life in Northern India, Illinois, University of Illinois Press, 1958.

LineBAugh, Peter, London Hanged: Crime and Civil Society in the Eighteenth Century, Cambridge, Cambridge University Press, 1993.

Menta, Nalin y Mona G. Mehta (eds.), Gujarat Beyond Gandhi, Identity, Conflict and Society, número especial de South Asian History and Culture, vol. 1, núm. 4, octubre de 2010.

Menon, Nivedita, "State/Gender/Community: Citizenship in Contemporary India", Economic and Political Weekly, vol. 33, núm. 5, enero de 1998, pp. PE3-PE10.

Menon, Ritu y Kamla Bashin, Borders and Boundaries: Women in India's Partition, New Brunswick, Rutgers University Press, 1998.

Merry, Sally Engle, "Anthropology, Law, and Transnational Processes", Annual Review of Anthropology, vol. 21, octubre de 1992, pp. 357-379. 
Merry, Sally Engle, Colonizing Hawai'i: The Cultural Power of Law, Princeton, Princeton University Press, 2000.

Mohapatra, Prabhu, "Restoring the Family: Wife Murders and the Making of a Sexual Contract for Indian Indentured Labourers in the British Caribbean Colonies", Studies in History, vol. 10, núm. 2, 1995, pp. 225-260.

Moore, Erin P., "Gender, Power, and Legal Pluralism", American Ethnologist, vol. 20, núm. 3, 1993, pp. 522-542.

NAder, Laura, Harmony Ideology: Justice and Control in a Zapotec Mountain Village, Stanford, Stanford University Press, 1991.

Nandy, Ashish, "Indian Popular Cinema as a Slum's Eye View of Politics", en Ashish Nandy (ed.), The Secret Politics of Our Desires: Innocence, Culpability and Popular Indian Cinema, Londres-Nueva York, Zed Books, 1999, pp. 1-19.

Noorani, A. G., Indian Political Trials, 1775-1947, Delhi, Oxford University Press, 2007.

Oomen, T. K., "The Concept of Dominant Caste", Contributions to Indian Sociology, vol. 4, núm. 1, 1970, pp. 73-83.

OrensteIn, Henry, Gaon: Conflict and Cohesion in an Indian Village, Princeton, Princeton University Press, 1965.

Owen, Nicholas, The British Left and India: Metropolitan AntiImperialism, 1885-1947, Oxford, Oxford University Press, 2007. PANDEY, Gyanendra, Remembering Partition: Violence, Nationalism and History in India, Cambridge, Cambridge University Press, 2002. Pendse, Sandeep, “Bombay's Satya and Satya's Bombay”, en Sujata Patel y Jim Masselos (eds.), Bombay and Mumbai: The City in Transition, Oxford, Oxford University Press, 2003.

Rajagopal, Arvind, "The Violence of Commodity Aesthetics: Hawkers, Demolition Raids, and a New Regime of Consumption”, Social Text, vol. 19, núm. 3(68), pp. 91-113.

RajAn, Rajeswari Sunder, "Shah Bano", Signs: Journal of Women in Culture and Society, vol. 14, núm. 3, 1989, pp. 558-582.

Rajan, Rajeswari Sunder, “The Ameena 'Case': The Female Citizen and Subject", en Rajeswari Sunder Rajan, The Scandal of the State: Women, Law and Citizenship in Postcolonial India, Durham, Duke University Press, 2003, pp. 41-71.

Rajan, Rajeswari Sunder, The Scandal of the State: Women, Law and Citizenship in Postcolonial India, Durham, Duke University Press, 2003.

Ramnath, Maia, Haj to Utopia: How the Ghadar Movement Charted Global Radicalism and Attempted to Overthrow the British Empire, Berkeley, University of California Press, 2012. 
RaO, Anupama, "Death of a Kotwal: Injury and the Politics of Recognition", en Shail Mayaram, M. S. S. Pandian y Ajay Skaria (eds.), Subaltern Studies XII, Nueva Delhi, Permanent Black-Ravi Dayad Publisher, 2005, pp. 140-187.

Rao, Anupama, "Problems of Violence, States of Terror: Torture in Colonial India”, en Steven Pierce y Anupama Rao (eds.), Discipline and the Other Body: Correction, Corporeality, Colonialism, Durham, Duke University Press, 2006, pp. 151-185.

Rao, Anupama, The Caste Question: Dalits and the Politics of Modern India, Berkeley, University of California Press, 2009.

RetZlaff, Ralph, "The Problem of Communal Minorities in the Drafting of the Indian Constitution”, en R. N. Spann (ed.), Constitutionalism in Asia, Londres, Asia Publishing House, 1963. Sanyal, Kalyan, Rethinking Capitalist Development: Primitive Accumulation, Governmentality, and Postcolonial Capitalism, Delhi, Routledge, 2007.

SAREEN, Tilak Raj, Indian Revolutionary Movement Abroad, 19051921, Nueva Delhi, Sterling, 1984.

SARKAR, Tanika, "Semiotics of Terror: Muslim Children and Women in Hindu Rashtra", Economic and Political Weekly, vol. 37, núm. 28, 2002, pp. 2872-2876.

Sen, Satadru, Disciplining Punishment: Colonialism and Convict Society in the Andaman Islands, Nueva Delhi-Oxford-Nueva York, Oxford University Press, 2000.

SEN, Satadru, "The Female Jails of Colonial India", Indian Economic and Social History Review, vol. 39, núm. 4, 2002, pp. 417-438.

Silvestri, Michael, Ireland and India: Nationalism, Empire and Memory, Nueva York, Palgrave Macmillan, 2009.

Singh, Ujwal Kumar, Political Prisoners in India, Delhi, Oxford University Press, 2001.

Singh, Ujwal Kumar, The State, Democracy, and Anti-Terror Laws, Nueva Delhi, Sage, 2007.

SINHA, Mrinalini, Specters of Mother India: The Global Restructuring of an Empire, Durham, Duke University Press, 2006.

Slate, Nico, Colored Cosmopolitanism: The Shared Struggle for Freedom in the United States and India, Cambridge, Harvard University Press, 2012.

SRInIVas, M. N., Collected Essays, Nueva Delhi, Oxford University Press, 2002.

SRInIVAS, M. N., "The Dominant Caste in Rampura", American Anthropologist, vol. 61, núm. 1, 1959, pp. 1-26.

StARr, June y Jane Collier (eds.), History and Power in the Study 
of Law: New Directions in Legal Anthropology, Ithaca, Cornell University Press, 1988.

Swaminathan, Padmini, "Prison as Factory: A Study of Jail Manufacture in the Madras Presidency", Studies in History, vol. 11, núm. 77, 1995, pp. 77-100.

Talbot, Ian, Pakistan: A Modern History, Londres, Hurst, 2009.

Toor, Saadi, The State of Islam: Culture and Cold War Politics in Pakistan, Londres-Nueva York, Pluto Press, 2011.

Turner, Victor, Schism and Continuity in an African Society: A Study of Ndembu Village Life, Oxford, Berg Publishers, 1996.

Vincent, Joan, Anthropology and Politics: Visions, Traditions, and Trends, Tucson, University of Arizona Press, 1990.

Visweswaran, Kamala, "Small Speeches, Subaltern Gender: Nationalist Ideology and Its Historiography", en Shahid Amin y Dipesh Chakrabarty (eds.), Subaltern Studies IX: Writings on South Asian History and Society, Nueva Delhi, Oxford University Press, 1996, pp. 83-125.

YANG, Anand A., "Disciplining 'Natives': Prisons and Prisoners in Early Nineteenth Century India”, South Asia, vol. 10, núm. 2, 1987, pp. 29-45.

ZamindaR, Vazira Fazila-Yacoobali, The Long Partition and the Making of Modern South Asia: Refugees, Boundaries, Histories, Nueva York, Columbia University Press, 2007. 